We suspect that this statement has arisen from a misconception of Kiell's words, while referring to the star in his Introduction to the true Astronomy or Astronomical Lectures, \&c., the first English edition of which appears to have been published in 1721 . In the third edition, 1739 (which is before us), at p. 56 , we read, after his reference to the phenomena in $\mathbf{1 5 7 2}$, "Leovitius, from the history of those times, tells us that in the time of the Emperor Otho, about the year 945, a new star appeared in Cassiopeia, just such a one as was seen in his time in the year 1572. And he brings us another ancient observation - that there was likewise seen in the northern region of the heavens, near the constellation Cassiopeia, in the year 1264, an eminently bright star, which kept itself in the same place, and had no proper motion. It is probable that these two stars might have been the same with that which was seen by Tycho, and that in about 150 years the same star may again make its appearance."

It will be remarked that Kiell makes no reference to any star seen midway between 945 and 1264 , nor between 1264 and 1556 , and it seems his meaning is clear, that Tycho's star, with a period of some 300 years, might make its appearance again "in about 150 years" from the time at which he wrote, as it might do were its changes accomplished in about three centuries. The misinterpretation of Kiell's words has led to his being credited with the opinion that the period is about 150 years, an idea which he probably never intended to expres:.

\section{ELECTRICITY APPLIED TO EXPLOSIVE PURPOSES}

I $N$ introducing the subject the lecturer indicated the principal advantage; which it had been early observed would result from a certain mode of firing explosive charges by electric current instead of by the ordinary fuzes, the best of which had inherent defects, greatly limiting their use for any but the simple:t operations. He traced the history and development of electric firing from the crude experimeats of Benjamin Franklin, about the year $175 \mathrm{I}$, through the various stages in which frictional electricity, volta-induction apparatus, and magnetoelectric machines had supplied the means of generating the current, the tendency of late years being to revert to a modified form of voltaic battery for one class of work, and to employ dynamoelectric machines for another class. The history and development of the low-tension or wire fuze, and of the various fuzes employed with electric currents of high tension, were also discussed, and their relative advantages, defects, and performances were described.

The only sources of electricity which at present thoroughly fulfilled the conditions essential in the exploding-agent for submarine mines vere constant voltaic batteries. They were simple of construction, comfaratively inexpensive, required but little skill or labour in their production and repair, and very little attention to keep them in constant good working order for long periods, and their action might be made quite independent of any operation to be performed at the last moment.

When first arrangements were devised for the application of electricity in the naval service to the firing of guns and so-called outrigger charges, the voltaic pile recommended itself for its simplicity, the readiness with which it could be put together and kept in order by sailors, and the considerable power presented and maintained by it for a number of hours. Different forms of pile were devised at Woolwich for boat and ship use, the latter being of sufficient power to fire heavy broadsides by branch circuits, and to continue in a serviceable condition for twenty-four hours, when they could be replaced by fresh batteries, which had in the meantime been cleaned and built up by sailors.

The Daniell and sand batteries first used in conjunction with the high-tension fuze for submarine mining service were speedily replaced by a modification of the battery known as Walker's, which was after some time converted into a modified form of the Leclanché battery.

The importance of being able to ascertain by tests that the circuits leading to a mine, as well as the fuzes introduced into that circuit, were in proper order, very soon became manifest ; and many instances were on record in the earlier days of submarine mining of the disappointing results attending the accidental disturbance of electric firing arrangements, when proper

I The fifth of the series of Six Lectures on the Applications of Electricity,
delivered on Thursday evening, April Ig, at the Institution of Civil delivered on Thursday evening, April 19, at the Institution of Civi means had not been known or provided for ascertaining whether the circuit was complete, or for localising any defect when discovered.

The testing of the Abel fuze, in which the bridge, or igniting and conducting composition, was a mixture of the copper phosphide and sulphide with potassium chlorate, was easy of accomplishment (by means of feeble currents of high tension), in proportion as the sulphide of copper predominated over the phosphide. Even the most sensitive might be thus tested with safety; but when the necessity for repeated testing, or even for the passing of a signal through the fuze, arose, as in a permanent system of submarine mines, the case was different, this fuze being susceptible of considerable alterations in conductivity on being frequently submitted to even very feeble test-currents, and its accidental ignition by such comparatively powerful test- or signalcurrents as might have to be employed, became so far possible as to create an uncertainty which was most undesirable.

Hence, and also because the priming in these fuzes was liable to some chemical change detrimental to its sensitiveness, unless thoroughly protected from excess of moisture, another form of high-tension fuze, specially adapted for submarine mining service, was devised at Woolwich. This, though much less sensitive than the original Abel fuze, was sufficiently so for service requirements, while it presented great superiority over the latter in stability and uniformity of electric resistance; and, though not altogether unaffected by the long-continued transmission of test-currents through it, the efficiency of the fuze was not affected thereby.

Although high-tension fuzes presented decided advantages in point of convenience and efficiency over the earlier form of platinum wire fuze, the requirements which arose, in elaborating thoroughly efficient permanent systems of defence by submarine mines, and the demand for a vattery for use in ships which would remain practically constant for long periods, caused a very careful consideration of the relative advantages of the bighand low-tension systems of firing to result in favour of the employment of wire fuzes for these services. In addition to the disadvantages pointed out there was an element of uncertainty, or possible danger, in the employment of high-tension fuzes, which, though partly eliminated by the adoption of voltaic batteries, in place of generators of high-tension electricity, might still occasionally constitute a source of danger, namely, the possibility of high-tension fuzes being accidentally exploded by currents induced in cables, with which they were connected, during the occurrence of thunderstorms, or of less violent atmospheric electrical disturbances.

Experiment, and the results obtained in military serviceoperations, had demonstrated that if insulated wires, immersed in water, buried in the earth, or even extended on the ground, were in sufficient proximity to one another, each cable being in circuit with a high-tension fuze and the earth, the explosion of any of the fuzes by a charge from a Leyden jar, or from a dynamo-electric machine of considerable power, might be attended by the simultaneous ignition of fuzes attached to adjacent cables, which were not connected with the source of electricity, but which become sufficiently charged by the inductive action of the transmitted current. It therefore appeared very possible that insulated cables extending to land- or submarinemine; in which high-tension fuzes were inclosed, might become charged inductively during violent atmospheric electrical disturbances to such an extent as to lead to the accidental explosion of mines with which they were connected. In a Report by von Ebner on the defence of Venice, Pola, and Lissa, by submarine mines, in 1866 , he refers to the accidental explosion of one of a group of sixteen mines during a heavy tbunderstorm, as well as to the explosion of some mines, by the direct charging of the cables, through the firing station having been struck by lightning. Two instances of the accidental explosion of tension fuzes by the direct charging of overhead wires during lightning discharges occurred in 1873 at Woolwich.

Subsequently an electric cable was laid out at Woolwich aleng the river bank below low-water mark, and a tension fuze was attached to one extremity, the other being buried. About eleven months afterwards the fuze was exploded by a charge induced in the conductor during a very heavy thunderstorm.

In consequence of such difficulties as these experienced in the special application of the high-tension fuzes to submarine purposes, the production of comparatively sensitive low-tension fuzes, of much greater uniformity of resistance than those employed in former years, was made the subject of an elaborate 
experimental investigation by the lecturer. Different samples of comparatively thin wires, made from commercial platinum, showed very great variations in electrical conductivity. Very considerable differences in the amount of forging to which the metal, in the form of sponge, had been subjected, did not importantly affect either its specific gravity or its conductivity, and the fused metal had only a very slightly higher degree of conductivity than the same metal forged from the sponge. The conductivity of very fine wires could therefore be but slightly affected by physical peculiarities of the metal, and the considerable differences in conductivity observed in different samples of platinum were therefore chiefly ascribable to variations in the degree of its purity. It appeared likely that definite alloys might furnish more uniform results than commercial platinum; experiments were therefore made with fine wires of German silver and of the alloy of sixty-six of silver with thirty-three of platinum employed by Matthiessen for the reproduction of B.A. standards of electrical re istance. Both were greatly superior to ordinary platinum iu regard to the resistance opposed to the passage of a current; Geriran silver was in its turn superior to the platinum-silver alloy; although the difference was only trifling in the small lengths of fine wire used in a fuze $(0.25$ inch), while the comparatively ready fusibility of platinumsilver contributed, with other physical peculiarities of the two alloys, to reduce German silver to about a level with it. Moreover, the latter did not resist the tendency to corrosive action exhibited by gunpowder and other more readily explosive agents which had to be placed in close contact with the wire bridge in the construction of a fuze, while the platinum-silver alloy was found to remain unaltered under corresponding conditions. Experiments having also been made with alloys of platinum with definite proportions of iridium, the metal with which it is chiefly associated, very fine wires of an alloy containing Io per cent. of iridium were eventually selected as eminently the best materials for the production of wire fuzes of comparatively high resistance and uniformity, this alloy being found decidedly superior in the latter respect as well as in point of strength (and therefore of manageableness in the state of very fine wire 0.001 inch in diameter) to the platinnm-silver wire. The fuzes now used in military and submarine services were made with bridge; of iridio-platinum wire containing to per cent. of the first-named metal.

The electrical gun-tubes in the navy were fired by means of a specially arranged Leclanché battery, and branch circuits worked to the different guns; in broadside firing it was important that the wire bridge of -any one of the gun-tubes which was first fired should be instantaneously fused on the passage of the current, so as to cut this branch out of circuit; in this respect the comparatively fusible platinum-silver alloy appeared to present an advantage, hence the naval electrical fuzes were made with bridges of that alloy. Uniformity of electrical resistance had become a matter of such high importance in the delicate arrangements connected with the system of submarine mines, as now perfected, that the very greatest care was bestowed upon the manufacture of service electric fuzes and detonators, which were in fact made in all their details with almost the precision bestowed upon delicate scientific instruinents, and the successful production of which involved an attention to minutiæ which would surprise a superficial observer.

One of the earliest applications of electricity to the explosion of gunpowder was the firing of guns upon proof at Woolwich by means of a Grove battery and a gun-tube, which was fired by a platinum wire bridge, a shunt arrangement being used for directing the current successively into the di-tinct circuits connected with the guns to be proved. When the hish-tension fuze had been devised, gun-tubes were made to which it was applied, and an exploder was arranged by Wheatstone, having a large number of shunts, so that as many as twenty-four guns might be brought into connection with the instrument, and fired in rapid succession by the depression of separate keys connected with each.

The firing of cannon as time-signals was an ancient practice in garrison towns, but the regulation of the time of firing the gun by electrical agency from a distance appears first to have been accomplished in Edinburgh, where, since 186I, the timegun had been fired by a mechanical arrangement actuated by a clock, the time of which is controlled electrically by the meantime clock at the Royal Observatory on Calton Hill.

Shortly after the establishment of the Edinburgh time.gun, others were introduced at Newcastle, Sunderland, Shields, Glas- gow, and Greenock. The firing of the gun was arranged for in various ways; in some instances it was effected either direct from the Observatory at Edinburgh, or from shorter distances, by means of Wheatstone's magnetoelectric exploders. At present there were time-guns at West Hartlepool, Swansea, Tynemouth, Kendal, and Aldershot, which were fired electrically, either by currents direct from London, or by local batteries, which were thrown into circuit at the right moment by means of relays, controlled from St. Martin's-le-Grand.

About thirteen years ago the electrical firing of guns, especially for broadsides, was first introducel into the navy, with the employment of the Abel high-tension gun-tube and voltaic piles. The gun-tubes then used were manufactured originally for the proof of cannon and for experimental artillery operations, and were of very simple and cheap construction. Experience proved them to be unfitted to withstand exposure to the very various climatic influences which they had to enc sunter in Her Majesty's ships, and in store in different parts of the world. The low tension gun tubes, having a bridge of very fine platinum-silver wire, surrounded by readily ignitible priming composition, was therefore adopted as much more suita'ble for our naval requirements.

The arrangements for broadsides or independent firing, and also for the firing of guns in turret-ships, had been very carefully and successfully elaborated in every detail, including the provision of a so-callea drill- or dummy electrical gun-tube, which was u:ed for practice and refitted by well $i$ structed sailors. The firing-keys, and all other arrangements co:nected with electrical gun-firing, were specially designed to insure safety and efficiency at the right moment.

The electric detonators for firing outrigger-torpedoes, or for other operations to be performed from open boats, corresponded, so far as the bridge was concerned, with the naval electric guntubes, and were fired with a specially fitted Leclanché battery. These electric appliances were now distributed throughout the navy, and the men were kept, by instruction and periodical practice, well versed in their use.

The application of electricity to the explosion of submarine mines, for purposes of defeoce and attack, received some attention from the Russians during the Crimean War, under the direction of Jacobi ; thus a torpedo, arranged to be exploded electrically when coming into collision with a vessel, wa; discovered at Yeni-Kale during the Kertsch expedition in 1855. Some arrangements were made by the British at the conclusion of the war to apply electricity to the explosion of $\operatorname{lar}_{3} \mathrm{e}$ powdercharges for the removal of sunken ships, \&c., in Sebastopol and Cronstadt Harbours. In 1859 , a system of submarine mines, to be fired tbrough the agency of electricity by operators on shore, was arranged by von Ebner for the defence of Venice, which, however, never came into practical operation. Early in I860 Henley's large magnetoelectric machine, with a supply of Abel fuzes, and stout indiarubber bags, with fittings to resist water-pressure, was despatched to China for use in the Peiho River, but no application appeared to have been made of them. The subject of the utilisation of electricity for purposes of defence, however, did not receive systematic investigation in England or other countries until some years afterwards, when the great importance of submarine mines, as engines of war, was demonstrated by the number of ships destroyed and injured during the war in America.

The application of electricity to the explosion of submarine mines was very limited during that war, but arrangements for its extensive employment were far advanced in. the hands of both the Federals and Confederates at the close of the war, mea of very high qualifications, such as Capt. Maury, Mr. N. J. Holmes, and Capt. McEvoy having worked arduou ly and successfully at the subject.

The explosion of submerged powder-charges, by mechanical contrivances, either of self-acting nature or to be set into action at desired periods, was accomplished as far back as 1583 , during the siege of Antwerp, by the Duke of Parma, and from that period to $\mathbf{1} 854$ mechanical devices of more or less ingenious and practicable character had been from time to time applied to some small extent, in different countries, to the explosion of torpedoes. The Russians were the first to apply self acting mechanical torpedoes with any prospect of success, and had the machines used for the defence of the Baltic been of larger size (they only contained 8 or $9 \mathrm{lb}$. of gunpowder), their presence would probably have proved very disastrous to some of the English ships which came into collision with and exploded them. 
Various mechanical devices for effecting the explosion of torpedoes by their collision with a ship were employed by the Americans, a few of which proved very effective. But although in point of simplicity and cost, a system of defence by means of mechanical torpedoes possessed decided advantages over any extensive arrangements for exploding submarine mines by electric agency, their employment was attended by such considerable risk of accident to those at whose hands they received application that, under many circumstances which were likely to occur, they became almost as great a source of danger to friend as to foe.

The most important advantages secured by the application of electricity as an exploding-agent of submarine mines were as follows:- They might be placed in position with absolute safety to the operators, and rendered active or passive at any moment from the shore; the waters which they were employed to defend were therefore never closed to friendly vessels until immediately before the approach of an enemy; they could be fixed at any depth beneath the surface (while mechanical torpedoes must be situated directly or nearly in the path of a passing ship), and they might be removed with as much safety as attended their application.

There were two distinct systems of applying electricity to the explosion of submarine mines. The most simple was that in which the explosion was made dependent upon the completion of the electric circuit by operators stationed at one or more posts of observation on shore; such a system depended, however, for efficiency, on the experience, harmonious action, and constant vigilance of the operators at the exploding- and observing. stations, and was, moreover, entirely useless at night, and in any but clear weather.

The other, which might also be used in conjunction with the foregoing, was that of self-acting mines, exploded either by collision with the ship, whereby circuit was completed through the inclosed fuze, or by the vessel striking a circuit closer, whereupon either the mine, moored at some depth beneath, was at once fired, or the necessary signal was given to the operator on shore.

Continental nations had followed in our footstep:, in providing themselves with equipments for defensive purposes by submarine mines, and the Danes, Swedes, and Norwegians had pursued the subject of submarine mine; with special activity and success.

In the United States the subject of the ntilisation of electricity as an exploding-agent for war purposes was being actively pursued, and important improvements in exploding instruments, electric fuzes, and other appliances had been made by Smith, Farmer, Hill, Striedinger, and others already mentioned, while $n$ ) individual had contributed more importantly to the development of the service of submarine explosions than General Abbot, of the United States Engineers.

Illustrations of actual results capable of being produced in warfare by submarine operations had hitherto been very few. but of the moral effects of submarine mines there had already been abundant illustrations. In the war carried on for six years by the Empire of Brazil and the Republic of Uruguay and the Argentine Republic of Paraguay, the latter managed, by means of submarine mines, to keep at bay, for the whole period, the Brazilian fleet of fifteen ironclads and sixty other men-of-war. In the Russo-Turkish war, submarine mines and torpedoes were a source of continued apprehension; and the French naval superiority was paralysed, during the Franco-German war, by the existence, or reputed existence, of mines in the Elbe.

The application of electricity to the explocion of military mines, and to the demolition of works and buildings, had been of great importance in recent wars in expediting and facilitating the work of the military engineer. The rapidity with which guns, carriages, \&c., were disabled and destroyed by a small party of men who landed after the silencing of the forts at Alexandria, illustrated the advantages of electrical exploding arrangement;, combined with the great facility afforded for rapid operations by the power possessed of developing the most violent action of gun-cotton, dynamite, \&c., through the agency of a detonator.

The application of electricity to the explosion of mines for land-defences during active war was not an easy operation, inasmiach as not only the preparation of the mines but also the concealment of electric cables and all appliances from the enemy entailed great difficulties, unless the necessary arrangements could have been made in ample time to prevent a knowledge of them reaching the enemy.
But few words were needed to recall to the minds of civil engineers the facilities which the employment of electricity to explosive purposes afforded for expediting the carrying out of many kinds of works in which they were immediately interested. Electrical blasting, especially in combination with rock-boring machines, had revolutioni-ed the operation of tunnelling and driving of galleries; and although in ordinary mining and quarrying operations the additional cost involved in the employment of fuzes, conductors, and the exploding-machine was not unfrequently a serious consideration, there were, even in those directions, many occasions when the power of firing a number of shots simultaneously was of great importance. There was little doubt, moreover, that accidents in mining and quarrying would be considerably reduced in number if electrical blasting were more frequently employed.

The conveniences presented by electric firing arrangements under special circumstances were interestingly illustrated by a novel proceeding at the launch of a large screw steamer at Kinghorn in Scotland, which was recently accomplished by placing small charges of dynamite in the wed ye-blocks along the sides of the keel and exploding them in pairs, hydraulic power being applied at the moment that the last wedge was shot away.

In the deepening of harbours and rivers and in the removal of natural or artificial submerged obstructions, the advantages of electric firing were so obvious that extended reference to them was unnecessary.

A substitute for electrical firing which had been applied with succes; to the practically simultaneous firing of several charges consisted of a simple modification of the Bickford fuze, which, instead of burning slowly, flashed rapidly into flame throughout its length, and hence had received the name of instantaneous fuze or lightning fuze. The fuze burned at the rate of about Ioo feet per second; it had the general appearance of the ordinary mining fuze, but was distinguished from the latter by a coloured external coating. Numerous lengths of this fuze were readily coupled up together so as to form branches leading to different shot-hole; which might be ignited together so as to fire the holes almost simultaneously. In the navy this fuze was used as a means of firing small gun-cotton charges to be throwa by hand into boats when these engaged each oth $\in \mathrm{r}$, the fuze being fired from the attacking boat by mean of a small pistol, into the barrel of which the extremity was inserted.

\section{THE IRON AND STEEL INSTITUTE}

$\mathrm{THE}$ annual meeting of this society took place at the Institution of Civil Engineers on May 9, Io, and II last. On the first day the chair was taken by the retiring president, Mr. Josiah T. Smith, but after some formal business had been gone through he vacated it in favour of the president elect, $\mathrm{Mr}$. B. Samuelson, M.M., F.R.S. The latter proceeded to read an able address, dealing mainly with the great progress which had taken place in the iron and steel industries since the Institute was founded in 1869. He remarked on the very large makes of pig iron which were now going on in American blast furnaces, and stated that these were found to be economical even as regards fuel and wear and tear of the lining. He then dwelt at some length on improvements in the manufacture of coke, especially with a view to recovery of the waste products. The deterioration which was feared would result as regards the coke itself had not appeared in the case of the Simon-Carvés ovens, worked by Messrs. Pease and Co., who were recovering oil and tar to the value of $4 s .2 d$. per ton of coal. Against this was to be set increased expenses to the amount of $\mathrm{I} s .4 d$. per ton of coke, and also interest on first cost and maintenance. He further referred to the Jameson process lately described before the Ir stitution of Mechanical En isineers, and observed that this principle was being applied to recover oil and ammonia from smouldering waste-heaps at the pit bank. Passing on to the manufacture of steel he spoke with much approval of the Bicheroux gas puddling furnaces at Ougré in Belgium, where gas obtained from slack was used for puddling, and gave more heat for steam-raising purposes than the old system. Speaking of the future demand for iron and steel, he pointed out that the United States had fifty times and Russia five times as many miles of railway per million of people as had our Indian Empire; and strongly urged the further development of railways in the latter country. The address also touched upo: many other points connected with iron and steel, such as the 